\title{
Fluorescence in situ hybridization (FISH) in food pathogen detection
}

\begin{abstract}
Diseases due to food borne microbial pathogens are major public health concern in the world. Different methods are used to detect food borne pathogens from different types of foods to prevent from these diseases. Out of those methods, molecular detection methods have received more concern in the recent past. Fluorescence in situ Hybridization is one of such methods used in the detection of food borne microbial pathogens. The present situation of using Fluorescence in situ Hybridization to detect food borne microbial pathogens is review in this article.
\end{abstract}

Keywords: fluorescence in situ hybridization, food borne pathogens, molecular detection methods
Volume 3 Issue 3 - 2018

\section{Dias PGI, Rathnayaka RMUSK}

Department of Food science and Technology, Sabaragamuwa

University of Sri Lanka, Sri Lanka

\author{
Correspondence: Rathnayaka RMUSK, Department of \\ Food science and Technology, Faculty of Applied Sciences, \\ Sabaragamuwa University of Sri Lanka, P.O. Box 02, Belihuloya, \\ Sri Lanka, Email udayarathnayaka@gmail.com
}

Received: February 12, 2018| Published: June 07, 2018

\section{Introduction}

Food borne diseases (FBDs) are of foremost public health concern in the world. Those are accountable for millions of deaths worldwide and placing a tremendous burden on the socioeconomic status of developing countries. Currently, reliable statistical estimates for the global influence of FBDs are not available. However, diarrhoeal diseases alone, which form a generous percentage of FBDs, kill 1.9 million children globally every year. ${ }^{1}$ The majority of FBDs are generated by the consumption of foods contaminated with pathogenic bacteria, viruses or parasites. Listeria monocytogenes, Escherichia coli O157:H7, Staphylococcus aureus, Salmonella enterica, Bacillus cereus, Vibrio spp., Campylobacter jejuni, Clostridium perfringens, Shiga toxin-producing Escherichia coli and norovirus are some common examples of such microorganisms. ${ }^{2}$ Mass scale food processors are generally implementing food quality management systems (e.g. ISO 9001) and food safety management systems (e.g. ISO 22000) throughout their entire food chain which restricting the access of food borne pathogens (FBPs) into particular food products. However, increasing demand for street foods and minimally processed foods yet has the risk. Therefore, detection, identification, characterization, and quantification of FBPs in foodstuffs with greater accuracy, sensitivity and rapidity are an utmost important proactive approach to eliminate FBDs.

Simple, easily adaptable and generally inexpensive culturing methods are traditionally exploited over several decays to detect FBPs. However, those methods are time-consuming (minimum 18 to 24 hours), labor-intensive, sometimes giving falsely negative results, and most importantly less sensitive for fewer microbial counts. Further, viable but non-culturable microbes cannot detect by those methods. ${ }^{3}$ On occasion, single FBP is enough to cause lethal infections. Hence, culture-independent rapid detection methods are important, particularly in the food industry, as they are able to detect FBP with great accuracy and sensitivity. However, expensiveness, complexity and requirement of expertise knowledge limited the fame of these culture independent methods. Rapid FBP detection methods can be categorized into three groups as Nucleic acid-based (NAB), biosensor-based (BB), and immunolgical-based (IB) methods. ${ }^{2}$ Among them, NAB methods are widely utilized in FBP detection. DNA and
RNA are the two nucleic acids present in the living organisms. DNA sequence is carrying genetic instructions to produce a specific amino acid sequence in a protein. RNA is mediate to synthesize protein according to the genetic instruction of DNA. There are specific and unique nucleotide sequences within FBP cells which are responsible for generating toxic proteins (e.g. shiga toxin by $E$ coli). In NAB methods these nucleotides are identified and read, hence confirm the presence of a particular pathogen. Polymerase chain reactions (PCR), nucleic acid sequence-based amplification (NASBA), loop-mediated isothermal amplification (LAMP) and microarray technology are some examples of NAB methods. Fluorescence in situ hybridization (FISH) also can categorize as a NAB method. However, it has not yet been routinely used to analyze and monitor pathogenic microorganisms in food products. FISH has additional benefits as it visualizes whole cells and targets ribosomal RNAs (or other abundant structures like multi-copy genes), which offers FISH with the ability to distinguish between viable organisms and dead materials. Correspondingly, the result can be obtained within few hours and less effort with high specificity and sensitivity. ${ }^{4}$ The purpose of this review is to give an overview of the current state of the FISH-testing in FBPs detection on diverse kinds of food matrix.

\section{Fluorescence in-situ hybridization}

\section{History}

The concept of applying molecular hybridization directly into the cytogenetic material is firstly founded by Pardue \& Gall ${ }^{5}$ and independently John et al. ${ }^{6}$ The method is called In Situ Hybridization (ISH). In ISH, radioactively labeled single-stranded DNA and 28S RNA are used as probes. In ISH, hybridized probes were observed in silver color through radiograph. The technique allowed detecting nucleic acid sequence inside a cell without disturbing its morphology or integrity. ISH was majorly utilized for detecting the chromosomal disorders and took the clues of several diseases as tumors of a wide range of species. Giovannoni et al., ${ }^{7}$ was the first researcher who used ISH for bacteriological detections. In the early 1990s introduction of fluorescence labeling displaced the radioactive labeling. In Delong et al., ${ }^{8}$ first used fluorescently labeled oligonucleotides for the uncovering of single microbial cells. ${ }^{9}$ With compare to radioactive 
probes, fluorescent probes are safer, give better resolution and do not need additional detection steps. Moreover, fluorescent probes can be labeled with dyes of different emission wavelength, therefore, allowing detection of several target sequences within a single hybridization step. ${ }^{9}$

\section{Basic elements of FISH}

Fluorescently labeled, synthesized nucleotide probe/prime and its complementary DNA/RNA sequence within the target cell are the basic FISH elements. Nucleotide probe can be DNA or RNA or else DNA/RNA mimics (PNA- peptide nucleic acid/ LNA- locked nucleic acid). They are commercially available or else can be prepared in laboratory levels and store under $-20^{\circ} \mathrm{C}$ for several months. Specificity, sensitivity, and ease of penetration are the major aspects when selecting a probe. Short probes make easy entree to the target but can carry fewer labels. Therefore, the usual probe contains 15 to 30 base pairs. $^{9}$ Probes are labeled either directly, by chemically or enzymatically bound to fluorescent nucleotides, or indirectly, by integration of reporter molecules. ${ }^{10} 16 \mathrm{~S}$ or $23 \mathrm{~S}$ rRNA is the majorly used target nucleotide since it is present in all living cells in fairly high amount. ${ }^{11}$ They are polygenetic markers and lot of sequence data available for probe designing. However, the less sensitivity of FISH protocols is compelled to utilize nucleic acids present in lower copy numbers, such as mRNA, plasmids or even single copy genes. Diversification of target nucleotides are recognized by genome sequence identification projects. ${ }^{12}$

\section{Basic steps of FISH}

The procedure contains following basic steps (Figure 1). (i) Fixation and permibilzation of the specimens, (ii) hybridization of the probe with a target nucleotide, (iii) wash to remove unbound probes and (iv) visualization and enumeration of the result. However, in food microbiology, further steps for the sample preparation as homogenization, pre-enrichment procedures or bacterial separation might be necessary. ${ }^{4}$

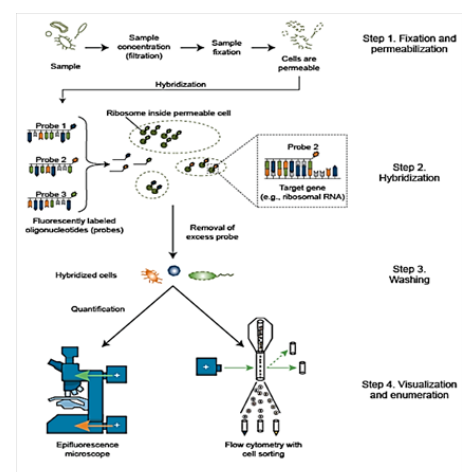

Figure I Steps in fluorescence in-situ hybridization

Source: Environmental Molecular Diagnostic, 2017

\section{Sample preparation}

FBPs identification is a predominant challenge in food analysis. Uneven distribution of target microorganism in a little number, the complexity of food matrix, and an enormous number of other competitive micro-flora in the same food create barriers to accurate detection. ${ }^{4}$ In FISH, there is another restriction as the food components with natural fluorescence activity, like chlorophyll in plant material and hemoglobin in meat are responsible for false results., ${ }^{413}$ Several pretreatments as pre-enrichment and centrifugation are assigned in sample preparation step to expel those obstacles. However, they are not universal or matrix specific.

\section{Fixation and permeabilization of the specimens}

Separated cells of interest are fixed into a cleaned glass slide, to preserve their morphology and integrity. Gelatin, Polylysine or Glutaraldehyde coated slides are used to minimize the tissue losses and maximum recovery of oligonucleotides. Precipitation agents such as ethanol or methanol and cross-linking agents such as formaldehyde are some successful fixative agents. Fixation method largely depends on target microorganism. For instance, formaldehyde or paraformaldehyde is recommended for gram-negative bacteria while ethanol, formalin or heat treatment is recommended for gram-positive bacteria. ${ }^{9}$ Fixation free FISH also grab the attention of researchers. ${ }^{14}$ It is reported that unfixed FISH minimize the sequencing biases introduced by crosslink between fixative agents and nucleotides as well as avoid possible cell lysis difficulties. ${ }^{14,15}$ Further, unfixed mammalian tissue has been shown to produce comparatively better imaging results. ${ }^{16}$ However, unfixed FISH is recommended for fresh samples since it is not preserving the sample as fixation. ${ }^{14}$ Unfixed oligonucleotide probes of Escherichia coli, Salmonella enterica and Pseudomonas putida were investigated in several studies, however, yet not in commercial level. (4,17,18 $^{\text {Target oligonucleotides }}$ are surrounded by proteins, lipids, etc., and that masked the access of fluorescent probes towards the target. Therefore, permeabilization procedures are often required. There is no matrix specific or universal protocol for permeabilization. However, HCL treatment for partial hydrolysis of proteins, detergent treatment for denaturing the lipid membrane components and RNase treatment for inactivate the RNAs and increase the DNA-DNA noise to signal ratio are some common approaches. Further, treatment with unspecific proteases (e.g. Savinase or Proteinase K) is applied to reduce the auto-fluorescence of the food matrices. ${ }^{13}$

\section{Hybridization, washing and visualization}

In hybridization, labeled probes bind with target nucleotide sequence and form 'probe-target hybrids'. Both should be denatured before hybridization and often formamide is added to reduce the melting point. ${ }^{19}$ Hybridization temperature, buffer stringency and number and length of nucleotides and number of $\mathrm{C}-\mathrm{G}$ bonds (stronger than A-T/U bonds) are the factors influence in the process. ${ }^{13}$ Postwashing procedures remove unbound single stranded DNA as well as nonspecifically bound DNA. Visualization can be performed either by florescence microscope or else flow cytrometry.

\section{Applications of FISH in food pathogen detection}

Applications of FISH are largely directed towards medicine and diagnostic field. Rapid and convenient identification of pathogens in the blood or the faeces and cytogenetic examinations to detect chromosomal disorders or tumor cells are the trending topics in molecular based research arena. FISH also utilize in ecology and environmental biology to study the composition, growth and changes of complex microbial communities and biofilms. ${ }^{4,20-22}$ In addition the method acts as an emerging tool in FBPs detection (Table 1). Nevertheless, this area of FISH possesses large gaps and requirement to upgrade. ${ }^{4}$ stated that FISH is in its infancy level with compare to molecular techniques as PCR. Some findings within the past decade on FISH in food pathogen detection are summarized in (Table 1). According to the literature, Salmonella spp. and Listeria 
spp. are the largely investigated pathogens through FISH. Most of the investigations are continued with the aid of artificially introduced (spiked) pathogens. Thus, it is debatable whether the findings can similarly apply to the naturally contaminated food matrix. Liquid, solid, processed and unprocessed matrices were evaluated by FISH, though, the protocols are not matrix specific.

Table I Application of Fish in FBPs detection

\begin{tabular}{|c|c|c|c|c|}
\hline Reference & $\begin{array}{l}\text { Pathogen/type of } \\
\text { contamination }\end{array}$ & Food matrix & $\begin{array}{l}\text { Target } \\
\text { probe type }\end{array}$ & $\begin{array}{l}\text { Remarks (enrichment period/fish methodology/ } \\
\text { sensitivity) }\end{array}$ \\
\hline 23 & $\begin{array}{l}\text { Salmonella spp. } \\
\text { (spiked) }\end{array}$ & $\begin{array}{l}\text { Lettuce, spinach, } \\
\text { parsley, carrot, } \\
\text { celery, tomato and } \\
\text { sweet corn roots }\end{array}$ & Not stated & confocal laser scanning microscopy (CLSM) \\
\hline 24 & $\begin{array}{l}\text { Yersinia spp. } \\
\text { (spiked) }\end{array}$ & minced pork meat & $\begin{array}{l}\text { I } 6 S \text { and } 23 S \text { rRNA } \\
\text { LNA }\end{array}$ & Use math-FISH in probe development \\
\hline 25 & $\begin{array}{l}\text { Escherichia coli } \\
\text { OI57 }\end{array}$ & $\begin{array}{l}\text { Ground beef Milk } \\
\text { (spiked) }\end{array}$ & PNA & $\begin{array}{l}100 \% \text { specificity, } 97.22 \% \text { sensitivity, } \\
\text { and } 98.33 \% \text { accuracy }\end{array}$ \\
\hline 26 & $\begin{array}{l}\text { Enterobacteriaceae } \\
\text { Pseudomonas spp. }\end{array}$ & Milk & I6S rRNA & $\begin{array}{l}7 \mathrm{~h} \text {, multicolor fluorescence in situ hybridization } \\
\text { (M-FISH), } \\
\text { micro-colony growth method (MMC-FISH) }\end{array}$ \\
\hline 27 & Salmonella spc. & $\begin{array}{l}\text { Powdered infant } \\
\text { Formula }\end{array}$ & $\begin{array}{l}\text { 23S rRNA, } \\
\text { PNA }\end{array}$ & $\begin{array}{l}\text { Detection of I CFU/I0 g in } 12 \mathrm{~h} \text {, } \\
100 \% \text { sensitivity and specificity }\end{array}$ \\
\hline 29 & $\begin{array}{l}\text { Salmonella spc. } \\
\text { (spiked) }\end{array}$ & Pork sausages & & $\begin{array}{l}4 \mathrm{~h} \text { enrichment, } \\
\text { Pre-enriched samples have high sensitivity }\end{array}$ \\
\hline 30 & Listeria spp. & & 23S rRNA & $\begin{array}{l}\text { I } 4 \mathrm{~h} \text { required with pre-enrichment step, } \\
\text { FISH on filter method to separate microbes }\end{array}$ \\
\hline 31 & Salmonella spp. & Tomato & Not stated & Tape-FISH \\
\hline 32 & Salmonella spp. & Pork sample & 23S rRNA & $\begin{array}{l}\text { Pre-enrichment step enhance the sensitivity of FISH } \\
\text { detection }\end{array}$ \\
\hline 33 & Clostridium perfringens & Food samples & I6S rRNA & $\begin{array}{l}\text { FISH on filter method was employed } 9 \mathrm{~h} \text { test } \\
\text { with } 2 \text { log CFU/g sensitivity }\end{array}$ \\
\hline 34 & Listeria monocytogenes & $\begin{array}{l}\text { Smoked salmon } \\
\text { Mozzarella cheese } \\
\text { Julienne cabbage } \\
\text { (spiked) }\end{array}$ & I6S rRNA & $\begin{array}{l}\text { I } 6 \mathrm{~h} \text { (cultivation } 12 \mathrm{~h} \text {, fixation I h, } \\
\text { air-drying } 45 \mathrm{~min} \text {, hybridization I h, washing } 30 \mathrm{~min} \text {, } \\
\text { counting } 30 \mathrm{~min} \text { ) required with aid of FISH on filter } \\
\text { method }\end{array}$ \\
\hline 36 & Salmonella spp. & Pork meat & 23S rRNA & $16 \mathrm{~h}$ pre-enrichment step \\
\hline 37 & $\begin{array}{l}\text { Mycobacterium avium } \\
\text { subsp. }\end{array}$ & Portable water & I6S rRNA PNA & $24 \mathrm{~h}$ enrichment \\
\hline 38 & $\begin{array}{l}\text { Salmonella spp. Listaria } \\
\text { spp. }\end{array}$ & $\begin{array}{l}\text { Barley plants } \\
\text { (spiked) }\end{array}$ & I6S rRNA 23S rRNA & CLSM \\
\hline 39,58 & Campylobacter spp. & Spiked drinking water & PNA I6s rRNA & $\begin{array}{l}\text { Membrane filtration technique brightness } \\
\text { of the hybridized cells is higher when they are viable }\end{array}$ \\
\hline 3 & Salmonella spp. & 18 different foods & 23S rRNA & $\begin{array}{l}\text { Convectional culturing methods are more sensitive than } \\
\text { FISH, } \\
\text { food matrix not interfering the results }\end{array}$ \\
\hline 40 & Escherichia coli. & $\begin{array}{l}\text { Ikura (Japanies sea } \\
\text { food) } \\
\text { Minced chicken meat }\end{array}$ & I6S rRNA, DNA & $\begin{array}{l}\text { FISH on filter method } 6 \mathrm{~h} \text { for enrichment and } \\
\mathrm{I} \mathrm{h} \text { FISH assay } 2 \log \text { CFU/g sensitivity }\end{array}$ \\
\hline 41 & Pseudomonas spp. & Milk & I6S rRNA & $2 \mathrm{~h}$ for FISH assay Flow cytometer \\
\hline 42 & Camphylobactor spp. & $\begin{array}{l}\text { Chicken products } \\
\text { Spiked and natural }\end{array}$ & I6S rRNA & $22 \mathrm{~h}$ pre-enrichment period \\
\hline
\end{tabular}

\section{Different ways of increasing sensitivity of FISH}

Less signal intensity can be identified as a major drawback of traditional FISH. Some researchers stated that FISH is less sensitive with compare to PCR techniques and even convectional culturing methods. ${ }^{3,42}$ Less permeabilization of target nucleotides and less nucleotide density of slowly growing, very small or metabolically inactive cells can largely accountable for signal depletion. Yet, permeabilisation should carefully balance to protect cell integrity. ${ }^{12}$ Therefore; an array of improved techniques is introduced to amplify the fluorescence signals in different steps of FISH.

\section{Increase sensitivity in sample preparation step}

This step basically comprises of pre-enrichment and microbial separation techniques, sometimes exploiting food matrix and species specific approaches. 


\section{Pre-enrichment}

Culture enrichment can perform even before FISH, which reported a considerable enhancement of detection sensitivity of FBPs. ${ }^{29,42}$ This enables multiplication of cells and nucleotides. Higher the targets, brighter the fluorescence signals. Enrichment period vary with the species. For instance, E-coli, an organism with high ribosomal content required comparatively less pre-enrichment time than Camphylobactor spp. or Listaria spp. Dilution of the interfering food matrix components is an additional advantage of enrichment. However, this step largely prolongs the detection time and do not improve the detection of viable but non culturable bacteria. Further, this method restricted the accurate determination and quantification of initial microbial load. ${ }^{4}$

\section{Microbial separation techniques}

Centrifugation (for liquid food matrices); mechanical, chemical or enzymatic separation (for solid food matrices) and filtration are the simplest, target non-specific isolation techniques. Sometimes interfering materials also isolated alone with microbes. ${ }^{4}$ Further, centrifugation can adversely affect the pathogen viability as the mechanical pressure developed and heat generated during the process. Therefore, pathogen specific isolation techniques are required. Immunogenic separation techniques (IMS) which use a bead coated with pathogen specific antibody ${ }^{43}$ and magnetic separation techniques (MS) which use a bead coated with metal hydroxides or lectins are examples for such methods. ${ }^{13}$ Tape FISH, Section FISH, and FISH on the filter are some other techniques developed to separate a representative sample for FISH analysis, also utilized in FBP detection. Tape fish acquired in detection of salmonella spp. in tomato (Table 1). Camphylobacter spp. and gallibacterium spp. detection in chicken liver and spleen were accomplished with the aid of section FISH. ${ }^{44,45}$ FISH on filter also utilized in FBPs detection of large variety of food matrices as milk, smoked salmon, cheese, ham, meat, beef, ikura (Japanese food made from salmon) and cabbage. ${ }^{30,33,34,40}$ However, the method is most effective in liquid foods. ${ }^{4}$

In tape FISH, sterile and transparent adhesive tape is attached to the food surface, which has the possibility of pathogens localization. FISH can directly perform on the tape or else the tape can contact with a specific culture media to enrich pathogens and detect microcolonies via microscope. The efficiency of cell capture/release by tape is depended on cell surface properties (e.g. moisture content, surface coatings) and mode of attachment (nonspecific adhesion/adhesion mediated by a specific structure as flagella). It is reported that $99 \%$ capture ability of fungi tape., ${ }^{4,31}$ These tapes are commercially available under different brand names. Further, untreated food component can dip in specific broth for overnight to separate and enrich cells, a time-consuming approach. ${ }^{46}$ Thin section of food sample as a tissue is used in section FISH. In FISH in filter method, microorganisms are separated into a filter membrane and FISH is performed on the filter or else enrich the microbes in a specific media. These methods are reduced unwanted inhibitors, hence, advantageous than the homogenizing whole sample. ${ }^{4}$

\section{Increase sensitivity in hybridization step}

This aspect is achieved through alteration of probe or target or else hybridization conditions as temperature and buffering capacity. This is the maximum diversified step in the FISH protocol. Yet, each and every diversification was not exploited in FBPs detection except PNA or LNA probing, multicolor FISH and flow FISH.

\section{Multiple probes for one target microorganism}

More than one probe can use to target multiple sites of $16 \mathrm{~S}$ or $23 \mathrm{~S}$ rRNA of target pathogen. Signals are amplified in 2-3 fold compared to traditional FISH. Normally, it is difficult to design several probes with the same specificity. ${ }^{12}$

\section{Multiple targets to a probe}

Target oligonucleotides can increase artificially. For instance, a sample is incubated with chloramphenicol $(\mathrm{CM})$, an inhibitor of protein synthesis, rRNA degradation and cell division, thus leading to an accumulation of rRNA in the cell. It is testified that, CM treatment increased the percentage of fluorescent cells to nearly $100 \%$ compared to untreated cells. ${ }^{47}$ Antibiotic activity of $\mathrm{CM}$ can adversely affect to microbial population, is a limitation of this method. ${ }^{4}$

\section{Helper oligonucleotides}

They are unlabeled nucleotides, are attached to the surrounding of the target site, hence open and facilitate the binding towards the target. This reported 25 fold signal amplification. ${ }^{4}$

\section{PNA probes}

PNA is a synthesized DNA in which the sugar phosphate backbone (negative charge) is replaced with a pseudo-peptide having comparatively high affinity to target. Hence, length of the probe can be shortened. Further, PNA can bind to the structures which DNA cannot. For instance, E. coli $\mathrm{O} 157$ serotype was specifically identified by PNA, which DNA could not. ${ }^{25}$ It is stated that PNA can hybridize in low salt concentration and high temperatures, whereas secondary structures consisting out of DNA or RNA dissolve. ${ }^{4}$ Further, unipolar nature of PNA increase the cell permeabilization, hence, reduces the hybridization time while enhancing the efficiency. PNA-FISH has reported 5 fold signal amplification than DNA. ${ }^{12}$ Comparatively high cost and lesser predictability of the results have avoided the application of PNA. However, the use of PNA probes in FBPs detection has increased significantly in recent years, particularly in dairy and poultry products. ${ }^{25,27,41,48,49}$

\section{Locked nucleic acids (LNA)}

This is a RNA analog, which the ribose ring locked by a methylene linkage between the $2^{\prime}$-oxygen and the $4^{\prime}$-carbon. This reduces the conformational flexibility of the ribose and increasing the local organization of the phosphate backbone. Enhancement of melting temperature is the basic advantage of LNA which can speed the hybridization process ${ }^{50}$ LNA was least utilize in FBPs identification with compare to PNA. However, Rohde et al. initiated to detect Yersinia spp. in pork using LNA probe in $2017 .{ }^{24}$ PNA and LNA are unnatural molecules, and they are not substrates for enzymes that modify DNA, RNA and proteins. Therefore, much more effective than DNA or RNA in FISH detection. ${ }^{4}$

\section{Bacterial chromosomal painting (BCP)}

The whole genome of the target organism is used as a probe. In here, all 24 chromosomes can be detected by allocating different color for each. Prolonging the hybridization time is a drawback of this method. BCP has been shown to permit differentiation of Salmonella serotype $^{51}$ and has also been applied to marine samples. ${ }^{52}$ This is the principle behind multicolor FISH (mFISH) and spectral cariotype (SKY). Salmonella spp., Listeria monocytogenes, Enterobacteriaceae and Pseudomonas spp. of bovine and sheep milk were tested using mFISH. ${ }^{26,53}$ 


\section{Catalyzed reporter deposition-CARD-FISH}

This is an enzyme-mediated signal amplification method, also called TSA (tyramide signal amplification) FISH. In here, horseradish peroxidase (HRP)-labeled oligonucleotide probes are utilized. In the presence of hydrogen peroxide, HRP converts tyramide (amine) into a radical intermediate which has the ability to bind to the electronrich surfaces of target oligonucleotides. Requirement of vigorous pretreatments (e.g. proteinase/lysozyme application enables the HRP to enter the cell) and hence loss of cell integrity is a drawback of this method. The method is heavily practice in marine biology. ${ }^{54-56}$

\section{Polynucleotide probes and RING-FISH}

Polynucleotide probes can range in length between 100 and several hundred base pairs. They are made of ssRNA or dsDNA, and carry multiple labels, either fluorescent dyes or digoxigenin/biotin for a secondary detection. This long probes are creating secondary network structure in intracellular and extracellular level, which allows ring shape fluorescence signals..$^{57,58}$ Due to its high copy number rRNA considered as the only suitable target for FISH. Instead of that targeting other nucleotides as mRNA, tmRNA, plasmid and chromosomal DNA also facilitate by RING-FISH and CARD-FISH. Numerous other FISH techniques were discussed by different authors particularly in medical diagnostic and environmental biological fields as fiber FISH, dope-FISH, raman- FISH and so on (Volpi and Bridger, 2008) which was not or rarely apply in FBPs detection up to date.

\section{Increase sensitivity in visualization step}

Fluoresce microscopy is the convectional FISH visualization technique which is surpassing by flow cytometer (Figure 1) due to its unique advantages as not rely on slides, manual counting and large sample can detect rapidly without labor cost. ${ }^{4}$

\section{Flow cytometry (flow-FISH)}

In flow FISH, laser-based technology is applied to count, sort, and profile cells in a heterogeneous fluid mixture. Therefore, the foods as tomato, spinach, spices and particularly milk are tested for FBPs using flow FISH. ${ }^{4,31,35,41}$

\section{Conclusion and future perspective}

FISH is an immerging trend in FBPs detection which is in its basic stage with compare to PCR based detection techniques. Some FISH protocols acquire as high as $85-90 \%$ of its total time for preenrichment step. ${ }^{40}$ Therefore, if scientists can find solutions to omit or automate the pre-enrichment step, quick results can obtain along with high sensitivity. Available literature demonstrated that FISH can successfully exploit in FBPs detection. However, adaptation of alterations to enhance the sensitivity is must to ensure great accuracy and sensitivity. Lack of standard protocols and automation steps, investigator has to anticipate the potential pathogen present in the food sample when selecting a probe are also drawbacks in FISH. Each and every FBPs detection method has pros and cons. Hence, selecting a suitable method is depending on objective, available facilities and finally the impact of the finding to the general population. For instance, developing countries are still relying on convectional culture base techniques and expired technologies can be a possible cause for their elevating counts of FBP outbreaks.

\section{Acknowledgements}

None.

\section{Conflict of interest}

The author declares no conflict of interest.

\section{References}

1. Falkenhorst G, Bagdonaite J, Lisby M, et al. Outbreak of group A streptococcal throat infection: don't forget to ask about food. Epidemiol Infect. 2008;136(9):1165-1171.

2. Fei Law JW, Mutalib NSA, Chan KG, et al. Rapid methods for the detection of foodborne bacterial pathogens: principles, applications, advantages and limitations. Front Microbiol. 2015;5:770.

3. Fang Q, Brockmann S, Botzenhart K, eat al. Improved detection of Salmonella spp. in foods by fluorescent in situ hybridization with 23S rRNA probes: a comparison with conventional culture methods. J Food prot. 2003;66(5):723-731.

4. Rohde A, Hammerl JA, Appel B, et al. FISHing for bacteria in food-A promising tool for the reliable detection of pathogenic bacteria? Food Microbiol. 2015;46:395-407.

5. Pardue ML, Gall JG. Molecular hybridization of radioactive DNA to the DNA of cytological preparations. Proc Natl Acad Sci. 1969;64(2):600 604.

6. John H, Birnstiel M, Jones K. RNA-DNA hybrids at the cytological level. Nature. 1969;223:582-587.

7. Giovannoni SJ, Delong EF, Olsen GJ, et al. Phylogenetic group-specific oligodeoxynucleotide probes for identification of single microbial cells. J bacteriol. 1988;170(2):720-726.

8. Delong EF, Wickham GS, Pace NR. Phylogenetic stains: Ribosomal RNA-based probes for the indentification of single cells. Science. 1989;243(4896):1360-1363.

9. Moter A, Göbel UB. Fluorescence in situ hybridization (FISH) for direct visualization of microorganisms. J Microbiol Methods. 2000;41(2):85112.

10. Volpi EV, Bridger JM. FISH glossary: an overview of the fluorescence in situ hybridization technique. Biotechniques. 2008;45(4):385-386.

11. Ludwig W, Schleifer K. Bacterial phylogeny based on 16 S and 23S rRNA sequence analysis. FEMS Microbiol Rev. 1994;15(2-3):155-173.

12. Zwirglmaier K. Fluorescence in situ hybridisation (FISH)-the next generation. FEMS Microbiology Letters. 2005;246:151-158.

13. Frickmann H, Zautner AE, Moter A, et al. Fluorescence in situ hybridization (FISH) in the microbiological diagnostic routine laboratory: a review. Crit Rev Microbiol. 2017;43(3):263-293.

14. Yilmaz S, Haroon MF, Rabkin BA, et al. Fixation-free fluorescence in situ hybridization for targeted enrichment of microbial populations. ISME J. 2015;4(10):1352-1356.

15. Wallner G, Fuchs B, Spring S, et al. Flow sorting of microorganisms for molecular analysis. Appl Environ Microbiol. 1997;63(11):4223-4231.

16. Dagerlind A, Friberg K, Bean A, et al. Sensitive mRNA detection using unfixed tissue: combined radioactive and non-radioactive in situ hybridization histochemistry. Histochemistry. 1992;98(1):39-49.

17. Silverman AP, Abe H, Kool ET. Quenched autoligation probes. In: Marx, Andreas, Seitz, Oliver editors. Molecular Beacons: Signalling Nucleic Acid Probes, Methods, and Protocols. Humana Press. 2008. p. 161-170.

18. Silverman AP, Kool ET. Quenched autoligation probes allow discrimination of live bacterial species by single nucleotide differences in rRNA. Nucleic Acids Res. 2005;33(15):4978-4986.

19. Liehr T, Kreskowski K, Ziegler M, et al. The Standard FISH Procedure. Fluorescence In Situ Hybridization (FISH). Springer; 2017. 
20. Franks AH, Harmsen HJ, Raangs GC, et al. Variations of bacterial populations in human feces measured by fluorescent in situ hybridization with group-specific 16S rRNA-targeted oligonucleotide probes. Appl Environmen Microbiol. 1998;64(9):3336-3345.

21. Pekar Zlotin M, Hirsch FR, Soussan Gutman L, Ilouze, et al. Fluorescence in situ hybridization, immunohistochemistry, and next-generation sequencing for detection of EML4-ALK rearrangement in lung cancer. Oncologist. 2015;20(3):316-322.

22. Tarnawski SE, Lara E. From environmental sequences to morphology: observation and characterisation of a paulinellid testate amoeba (Micropyxidiella edaphonis gen. nov. sp. nov. Euglyphida, Paulinellidae) from soil using fluorescent in situ hybridization. Protist. 2015;166(2):264-270.

23. Kljujev I, Raicevic V, Vujovic B, et al. Salmonella as an endophytic colonizer of plants-A risk for health safety vegetable production. Microb Pathog. 2018;115:199-207.

24. Rohde A, Hammerl JA, Appel B, et al. Differential detection of pathogenic Yersinia spp. by fluorescence in situ hybridization. Food Microbiol. 2017;62:39-45.

25. Almeida C, Sousa J, Rocha R, et al. Detection of Escherichia coli O157 by peptide nucleic acid fluorescence in situ hybridization (PNA-FISH) and comparison to a standard culture method. Appl Environ Microbiol. 2013;79(20):6293-6300.

26. Yamaguchi N, Kitaguchi A, Nasu M. Selective enumeration of viable Enterobacteriaceae and Pseudomonas spp. in milk within $7 \mathrm{~h}$ by multicolor fluorescence in situ hybridization following microcolony formation. J Biosci Bioeng. 2012;113(6):746-750.

27. Almeida C, Azevedo NF, Fernandes R, et al. Fluorescence in situ hybridization method using a peptide nucleic acid probe for identification of Salmonella spp. in a broad spectrum of samples. Appl Environ Microbiol. 2010;76:4476-4485.

28. Angelidis AS, Tirodimos I, Bobos M, et al. Detection of Helicobacter pylori in raw bovine milk by fluorescence in situ hybridization (FISH). Int $\mathrm{J}$ Food Microbiol. 2011;151(2):252-256.

29. Rathnayaka R. Effect of sample pre-enrichment and characters of food samples on the examination for the Salmonella by plate count method and fluorescent in situ hybridization technique. American Journal of Food Technology, 2011;6(9):851-856.

30. Fuchizawa I, Shimizu S, Kawai Y, et al. Specific detection and quantitative enumeration of Listeria spp. using fluorescent in situ hybridization in combination with filter cultivation (FISHFC). J Appl Microbiol. 2008;105(2):502-509.

31. Bisha B, Brehm Stecher BF. Simple adhesive-tape-based sampling of tomato surfaces combined with rapid fluorescence in situ hybridization for Salmonella detection. Appl Environ Microbiol. 2009;75(5):1450-1455.

32. Vieira Pinto M, Oliveira M, Aranha J, et al. Influence of an enrichment step on Salmonella sp. detection by fluorescent in situ hybridization on pork samples. Food Control. 2008;19(3):286-290.

33. Fuchizawa I, Shimizu S, Ootsubo M, et al. Specific and rapid quantification of viable Listeria monocytogenes using fluorescence in situ hybridization in combination with filter cultivation. Microb Environ. 2009;24(3):273-275.

34. Shimizu S, Ootsubo M, Kubosawa Y, et al. Fluorescent in situ hybridization in combination with filter cultivation (FISHFC) method for specific detection and enumeration of viable Clostridium perfringens. Food Microbiol. 2009;26(4):425-431.

35. Laflamme C, Gendron L, Turgeon N, et al. Rapid detection of germinating Bacillus cereus cells using fluorescent in situ hybridization. Journal of Rapid Methods \& Automation in Microbiology. 2009;17(1):80-102.
36. Vieira Pinto M, Oliveira M, Bernardo F, eta 1. Rapid detection of Salmonella sp. in pork samples using fluorescent in situ hybridization: a comparison with VIDAS ${ }^{\circledR}-S L M$ system and ISO 6579 cultural method. Arquivo Brasileiro de Medicina Veterinária e Zootecnia. 2007;59(6):1388-1393.

37. Lehtola MJ, Torvinen E, Miettinen IT, et al. Fluorescence in situ hybridization using peptide nucleic acid probes for rapid detection of Mycobacterium avium subsp. avium and Mycobacterium avium subsp. paratuberculosis in potable-water biofilms. Appl Environ Microbiol. 2006;72(1):848853.

38. Kutter S, Hartmann A, Schmid M. Colonization of barley (Hordeum vulgare) with Salmonella enterica and Listeria spp. FEMS Microbiol Ecol. 2006;56(2):262-271.

39. Lehtola MJ, Loades CJ, Keevil CW. Advantages of peptide nucleic acid oligonucleotides for sensitive site directed 16S rRNA fluorescence in situ hybridization (FISH) detection of Campylobacter jejuni, Campylobacter coli and Campylobacter lari. J Microbiol Methods. 2005;62(2):211-219.

40. Ootsubo M, Shimizu T, Tanaka R, et al. Seven-hour fluorescence in situ hybridization technique for enumeration of Enterobacteriaceae in food and environmental water sample. J Appl Microbiol. 2003;95(6):1182-1190.

41. Gunasekera T, Dorsch M, Slade M, et al. Specific detection of Pseudomonas spp. in milk by fluorescence in situ hybridization using ribosomal RNA directed probes. J Applied Microiol. 2003;94(5):936-945.

42. Moreno Y, Hernández M, Ferrús MA, et al. Direct detection of thermotolerant campylobacters in chicken products by PCR and in situ hybridization. Res Microbiol. 2001;152(6):577-582.

43. Mandal P, Biswas A, Choi K, et al. Methods for rapid detection of food borne pathogens: an overview. American Journal of Food Technology. 2011;6(2):87-102. 25

44. Bojesen AM, Christensen H, Nielsen OL, et al. Detection of Gallibacterium spp. in chickens by fluorescent $16 \mathrm{~S}$ rRNA in situ hybridization. J Clin Microbiol. 2003;41(11):5167-5172.

45. Schmid MW, Lehner A, Stephan R, et al. Development and application of oligonucleotide probes for in situ detection of thermotolerant Campylobacter in chicken faecal and liver samples. Int J Food Microbiol. 2005;105:245-255.

46. Ercolini D, Villani F, Aponte M, et al. Fluorescence in situ hybridisation detection of Lactobacillus plantarum group on olives to be used in natural fermentations. Int J Food Microbiol. 2006;112(3):291-296.

47. Ouverney CC, Fuhrman JA. Increase in Fluorescence Intensity of $16 \mathrm{~S}$ rRNA In Situ hybridization in natural samples treated with chloramphenicol. Applied and Environmental Microbiology. 1997;63(7):2735-2740.

48. Almeida C, Azevedo N, Iversen C, et al. Development and application of a novel peptide nucleic acid probe for the specific detection of Cronobacter genomospecies (Enterobacter sakazakii) in powdered infant formula. Applied and Environmental Microbiology. 2009;75(9):2925-2930.

49. Stender H, Oliveira K, Rigby S, et al. Rapid detection, identification, and enumeration of Escherichia coli by fluorescence in situ hybridization using an array scanner. J Microbiol Methods. 2001;45(1):31-39.

50. Braasch DA, Corey DR. Locked nucleic acid (LNA): fine-tuning the recognition of DNA and RNA. Chem Biol. 2001;8(1)1-7.

51. Lanoil BD, Giovannoni SJ. Identification of bacterial cells by chromosomal painting. Applied and environmental microbiology. 1997;63(3)11181123.

52. Lanoil BD, Carlson CA, Giovannoni SJ. Bacterial chromosomal painting for in situ monitoring of cultured marine bacteria. Environmental microbiology. 2000;2(6):654-665. 
53. Oliveira M, Blasco L, Ferrer S, et al. Rapid and simultaneous detection of Salmonella spp. and Listeria monocytogenes in milk by fluorescent in situ hybridisation. Revista Portuguesa de Ciências Veterinárias. 2004;99(552):215-218.

54. Eickhorst T, Tippkötter R. Improved detection of soil microorganisms using fluorescence in situ hybridization (FISH) and catalyzed reporter deposition (CARD-FISH). Soil Biology and Biochemistry. 2008;40(7):1883-1891.

55. Kubota K. CARD-FISH for environmental microorganisms: technical advancement and future applications. Microbes Environ. 2013;28(1):3-12.
56. Pernthaler A, Pernthaler J, Amann R. Fluorescence in Situ hybridization and catalyzed reporter deposition for the identification of marine bacteria. Appl Environ Microbiol. 2002;68(6):3094-3101.

57. Zwirglmaier K, Ludwig W, Schleifer KH. Recognition of individual genes in a single bacterial cell by fluorescence in situ hybridization-RINGFISH. Mol Microbiol. 2004;51(1):89-96.

58. Pratscher J, Stichternoth C, Fichtl K, et al. Application of recognition of individual genes-fluorescence in situ hybridization (RING-FISH) to detect nitrite reductase genes (nirK) of denitrifiers in pure cultures and environmental samples. Applied and Environmental Microbiology. 2009;75(3):802-810. 